\title{
Covid 19, Quarantine Confronting Economic Growth, Social Challenges and Health Spending
}

\author{
Sawssen NAFTI \\ Faculty of Economics and Management of Sousse Laboratory, University of Sousse Street of Khalifa El \\ KarouiSahloul - BP $n^{\circ} 526$ - 4002 Sousse Tunisia \\ corresponding author: sawssen_nafti@yahoo.fr \\ ORCID identifier: 0000-0002-4022-7467
}

\begin{abstract}
This paper is a theoretical study of the impact of quarantine, economic growth and health spending on the spread of the Corona virus. We found, the greater the population density in cities, the greater the spread of the virus. This confirms the importance of quarantine in combating the spread of the virus. And why does the number of injuries increase in major countries more than others. In this way, quarantine have a negative effects in economic growth and social Challenges. In other way, quarantine slows economic growth and have a bad effects on increasing problems in families and in suicide rates. We conclude also that gaps in pandemic preparedness already existed before COVID-19, demands the restructuring of public spending in the health sector.
\end{abstract}

Keywords: covid19- quarantine-economic growth- social Challenges - health spending JEL classification: Q18- A14- I13

\section{1- Introduction}

The Coronavirus pandemic (COVID-19) is one of the world's greatest historical crises. It raised in the same time health and economic issues with questioning about this disease and its treatments, also its social and economic effects. With the increase in the number of infected and dead people, which prompts us to reflect on public spending on health. The objective of this paper is to study the impact of economic growth and health spending on the spread of the Coronavirus.

This study is organized as follow: Firstly, we give the notion of COVID-19 disease and its propagation. Secondly, we show a review of previous literature on the corona virus, Thirdly, we explore the notion of the quarantine and its economic and social effects and finally we give a concluding remarks of the importance of public spending in the health sector to solve coronavirus.

\section{2- COVID 19: Notion and evolution}

Coronavirus disease (COVID-19), a type of coronavirus that arose in January 2020 in Wuhan, China. COVID-19 caused both a global pandemic, and uncovered the global unpreparedness of healthcare systems. Being unable to absorb the overload of COVID-19 patients in emergency rooms and intensive care units, Due to safety regulations obligatory to respect social distancing. Both hospitals and clinics were forced to decrease in-person clinic visits and surgeries by the half worldwide, resulting a reduction in surgical revenues greater than revenues from emergency rooms and intensive care units (Grays 2020). In turn, the reassignment of health doctors and nurses without training or practice in emergency medicine to emergency departments to treat COVID-19 patients, left them with very high levels of stress also with burnout, forcing some to take early retirement or seek alternative settings (Grays 2020) ${ }^{1}$.

The coronavirus was revealed and propagate to the world "suddenly", in the end of 2019 firstly in China , after that gradually during 2020 on the world territory. In this way, The Covid-19 pandemic has shaken the world.

${ }^{1}$ Economies 2020, 8, 60; doi:10.3390/economies8030060 
Historians have cited the existence of pandemics in some respects similar in 1956-1958 and also in 1968-1969, such as the SARS epidemic in 2002-2003. The characteristic of the 2020-2021 pandemic is mainly due to its global scale and large geographical distribution, the totality of continents being affected, furthermore the very fast characterization of COVID 19 and the increasing of number of tests, also the equally rapid experimentation of both therapies and vaccines. Specially, this global health crisis is specified by the rigorous measures taken by the public authorities in order to avoid the congestion of health systems such as travel restrictions, obligation of the isolation of people carrying the COVID19, screening (variable depending on the country), specially, in a large number of countries, the practice of different types of general confinement of population gold of curfews. These measures have various consequences on the usual temporalities and have overturned habits and perceptions. But, have a good results, because greater the population density in cities, the greater the spread of the virus. This confirms the importance of quarantine in combating the propagation of the coronavirus. Besides, quarantine have various limits. containment, a good method that has proven itself for more than six centuries. However, what happens when people are locked in their homes for 30 or 40 days? in china, for example, there have been reports of suicides for fear of the corona virus, some will fight each other.

A major health crisis which has revealed in different ways the limits of the majority of modern health systems. While it seemed like a reality far away on the African continent, in the begging in December 2019, Affecting the majority of countries in Asia and Europe, the acceleration of propagation of the coronavirus in the periode of late February-early March 2020 in majority of African countries made it a global reality. Adds, the World Health Organization (WHO) announced on March 11, 2020 that the COVID-19 is a big pandemic. It afterwards invited the States to establishment of suitable health systems in order to care the sick and more control the propagation of the virus.

In terms of coronavirus morbidity and mortality, the African continent remains less affected than the rest of the world. In this way, in May 2020, more than 4 million people tested positive for coronavirus worldwide, more than 70,000 were located in Africa, Then, the caution is in the aim as of June 14, there were 242,000 cases on the continent for a total about of 7.7 million, or $3.1 \%$. the number of people decided on the same day, June 14 was 6,000 cases, in same day of $2.5 \%$, twice lower than the world average of $5.5 \%$. despite the scale of the pandemic has been smaller specially on the African continent, However, The number of people infected calls for caution. furthermore, the factors of virus evolution unknown yet, mostly, in terms of the possibility of the mutations and new waves of infection of the virus. This caution is very necessary and given the fragility of health systems on this continent.

In this situation caracterised by the absence of a vaccine against coronavirus imposed the presence of very quickly solutions, as a barrier measures choosed to be the palliative good solution. Also, physical distancing and washing hands with soap or hydro-alcoholic solutions is necessary. In addition, a different measures of restricting individual and collective freedoms are taken in order to reduce physical contact: closure of school and university, stopping sports competitions, confinement of populations, limited of interurban transport, curfews, etc. Both the defense and security forces are obliged to control with barrier measures and restrictions specially on the mobility of populations, in aim to limit the rapidity of spread of coronavirus. Restrictive measures may be in a certain way be understood in sight of the important rate of evolution of the pandemic and in a context where the covid 19 is not well known.

The virus provoked many reactions, specially due to the fact that they had direct and often various negative consequences on the living conditions people, especially in African cities where a large rate of population work in the informal sector.

the economy is gradually resuming on the continent (partial opening of schools, resumption of the majority of economic activities...) particularly in the most affected countries, accompanied by a relaxation in compliance with these barrier measures, many questions arise such us: what will be the evolution of coronavirus on the world? What are the consequences of the covid19 and in specially restrictive measures on household income, and Therefore their access to basic social services as health and education? What are the different consequences of school closures on the quality of learning in medium and long term? Are the corrective solutions proposed by governments sufficiently effective to limit the probable negative effects on the quality of education? What are the various medium and long term consequences of the crisis on both health supply and demand? Will health systems learn the good lessons they need for the future? 
DOI: $\underline{10.51386 / 25815946 / \mathrm{ijsms}-\mathrm{v} 4 \mathrm{i} 5 \mathrm{p} 122}$

If the coronavirus pandemic has and will have many social, demographic and economic effects in the short, medium and long terms, we could also wonder if this coronavirus could not also be an occasion. in various ways for the African continent in particularly: In this way, we have noted how the closure of borders has encourage each country to develop its national production, for example the local production of silencers, hand wash basins, hydroalcoholic gels... Is an opportunity of this crisis to permanently transform its economies to make them less extroverted and more dependent on the outside? also the closure of schools and universities has revealed, once again, the very urgent need to invest in both distance education and training technologies.

\section{3-Historic of quarantine quarantine is a 600-year-old method. \\ 1374: facing the black plague epidemic \\ 1423: to facilitate quarantine, lazards are invented \\ 1720: to try to stop the plague epidemic \\ 1955: the smallpox epidemic}

containment, a method that has proven itself for more than six centuries. here is a little history of the quarantine:

A little further in Our reflection, among the Muslims confinement or quarantine is for 14 centuries more than 1400 years at least implemented by the prophet mohamed, is the first one spoke of confinement 1400 years. The confinement of the population was done in the nineteenth century for cholera in Marseilles.

\section{4-Limits of quarantine}

Results of the Coronavirus, science is outdated, society locked up, the economy shattered and altered policies. All production cost optimization strategies, maximization of income to the detriment of employment and the well-being of society, are found facing the wall.

The 2019 Coronavirus pandemic will undoubtedly remain with the closure of borders, the most advanced countries were brought to their knees. They could no longer ensure their food self-sufficiency nor basic health needs, mainly because of the subcontracted production chains, mostly in China. Strategies that have been put in place with the sole vision of egocentric competitiveness, increasingly moving away from value chains and supply, on the basis of openings of trade and globalization. A globalization that has been destroyed by the exchange of information, of conference calls digitized, and messages of hope. The world scene is being revisited. Indeed, the economic and political geostrategy has begun its transformation towards a new form of normal, perhaps more human and more docile towards the environment.

- Increase in the number of people who have committed suicide

Since the start of the COVID-19 pandemic, maintaining good mental health has been at the heart of concerns, both among policy makers and health professionals.

The World Health Organization (WHO) has also expressed concern about the consequences psychosocial effects of the pandemic. She reports that the isolation measures that affect our daily lives could lead to increased loneliness, anxiety and symptoms of depression as well excessive consumption of alcohol and drugs and possibly have a negative impact on suicidal behavior. with the loss of income of many employers and the numerous layoffs, this health crisis is also an economic crisis, to mitigate its impacts.

\section{-Increase in family problems and increase in the percentage of divorce \\ Divorce rates are increasing around the world, and relationship experts warn the pandemic-induced break-up curve may not have peaked yet.the family lies locked in a small house with the stress of corona virus, increase of violence within the family, whether between the couple or with children. which leads to an increase in the percentage of divorce}

\section{- Increase in food security problems and health problems}

The Coronavirus pandemic that has spread quickly. and widely around the world since the end of 2019 has had various implications both for food security and nutrition. The family is locked up day and night, the only way to pass the time is to prepare menus rich in dough and sugar and to eat all the time ,spend the day and night eating especially the paws and cakes, chocolate to increase the hormone of happiness and forget corona virus.

\section{5- Conclusion}

The coronavirus disease was revealed to the world "suddenly", to the general public, towards the end of 2019 in 
China first, and then gradually during the first quarter of 2020 around the world. However, The Covid-19 pandemic has created an unprecedented situation in the world. It affects both economic and social life, and began one of the world's greatest historical crises. The quarantine is the only solution adapted by the most nations. In order to reduce the number of contaminated and dead people and stopped the spread of the virus with the presence of different types of vaccine .To conclude, quarantine is the only solution to reduce the contamination of people but it has several negative effects on the economy and the social life. Such as slowing economic growth and the increase in the number of people who commit suicide ( people are jailed in small houses).

Challenges remain, based specially on human nature, due to the willingness to expend both time and energy does not extend to an emergency such as a pandemic. This paper conclude also that gaps in pandemic preparedness already existed before COVID-19, demands the restructuring of public spending in the health sector.

\section{References}

[1] ADB Briefs (2020) "The Economic Impact of the COVID-19 Outbreak on Developing Asia," No. 128, 6 March 2020, DOI: http://dx.doi.org/10.22617/BRF200096

[2] Barredo, Lauren. (2020). Implications of COVID-19 for Public Health and the SDGs. New York: Sustainable Development Solutions Network. Available online: https://www.unsdsn.org/covid-19-webinar (accessed on 5 March 2020).

[3] Ben Hammouda, H. et M. H. Bchir (2020) «L’impact économique du COVID-19 sur la Tunisie et un programme de sauvetage de l'économie,» Leaders.

[4] Boone, L., D. Haugh, N. Pain and V. Salins (2020) "Tackling the fallout from COVID-19" in Economics in the time of COVID-19. https://doi.org/10.13106/jafeb.2020.vol7.no10.543

[5] Chemingui, M. et R. Ben Jelili (2020) "Will COVID-19 trigger a massive fall in FDI flows to the Arab region?" The Forum, Economic Research Forum, 21 avril 2020. https://theforum.erf.org. eg/2020/04/19/will-COVID-19-trigger-massive-fall-fdi-flowsarab-region.

[6] Grays, D. (2020). The Lasting Impacts of COVID-19 on the Health Care System. Texas A\&M University Health Science. Available online: https://today.tamu.edu/2020/04/22/the-lasting-impacts-of-covid-19-on-the-healthcare-system/ (accessed on 17 May 2020)

[7] IACE (Institut Arabe des Chefs d'Entreprises). 2020. L'impact du covid19 sur les entreprises tunisiennes. Tunis: IACE.

[8] Hatheway, L. (2020) “A COVID-19 Emergency Response Plan,” Project Syndicate.

[9] International Labor Organization (2020) “COVID-19 and world of work: Impacts and responses" ILO Monitor 1st Edition, https://www.ilo.org/wcmsp5/groups/public/---dgreports/---dcomm/documents/ briefingnote/wcms_738753.pdf

[10] Kang, K. et C. Rhee (2020) “A Post-Coronavirus Recovery in Asia-Extending a "Whatever it Takes" Lifeline to Small Businesses," https://blogs.imf.org/2020/04/23/a-post-coronavirus-recovery-in-asia-extending-a-whatever-it-takes-lifeline-to-small businesses/?utm_medium=email\&utm_source=govdelivery

[11] Ke, Xu, Priyanka Saksena, and Alberto Holly. (2011). The Determinants of Health Care Sector, a Country Level Panel Data Analysis. World Health Organization: Results for Development Institute. Available online: https://www.who.int/health_financing/documents/report_en_11_deter-he.pdf (accessed on 1 May 2020).

[12] McKinsey (2020a) COVID-19: Briefing note, March 16, 2020, https://www.mckinsey.com

[13] Mckinsey (2020b) “Tackling COVID-19 in Africa," https://www.mckinsey.com/featured-insights/ middle-east-and-africa/tacklingCOVID-19-in-africa

[14] McKibben and Fernando (2020) "The Global Macroeconomic Impacts of COVID-19: Seven Scenarios" https://www.brookings.edu/research/the-global-macroeconomic-impacts-of-COVID-19-seven-scenarios

[15] Smith-Bingham, R. and K. Hariharan (2020) "This is the impact of the Coronavirus on business," World Economic Forum

[16] World Bank. 2020. Tunisia COVID-19 response project. Washington, DC: World Bank.

[17] https://projects.worldbank.org/en/projects-operations/project-detail/P173945?lang=en\&tab=overview, accessed April

27,2020 